\title{
Energía eólica en la región euromediterránea: desarrollo y perspectivas
}

\author{
Francisco M. Fernández LatorRe y Jesús Ventura FernándeZ \\ Departamento de Geografía Física y Análisis Geográfico Regional \\ Universidad de Sevilla
}

Recibido: 13 de Junio de 2011

Enviado a evaluar: 14 de Junio de 2011

Aceptado: 5 de Octubre de 2011

\section{RESUMEN}

Este trabajo caracteriza en una primera aproximación al desarrollo eólico en la región euromediterránea, e identifica las principales iniciativas en marcha y condicionantes de desarrollo. Se estudia el caso de la ordenación de la energía eólica en el área del Estrecho de Gibraltar. Se analiza el desarrollo eólico en los territorios euromediterráneos comparando distintos estados y comunidades autónomas españolas mediante diversos indicadores. Se señalan países clave por su potencial y políticas de fomento eólico.

Palabras clave: energía eólica; región euromediterránea; planificación energética

\section{Wind power in the Euro-Mediterranean region: development and prospects}

\begin{abstract}
This work is a first approach to wind development in the Euro-Mediterranean región and identifies the major initiatives underway as well as development conditions. It includes a study case of wind power management in the Strait of Gibraltar area. Wind development is analyzed in the Euro-Mediterranean territories by comparing Spanish regions with different States using various indicators. Key countries are noted for their potential and policies to promote wind based alternatives.
\end{abstract}

Keywords: wind power, Euro-Mediterranean region, energy planning

\section{Énergie éolienne dans la région euro-méditerranéenne: développement et perspectives}

\section{RÉSUMÉ}

Ce travail est un premier approchement au développement éolien dans la région euroméditerranéenne, et identifie les principales initiatives en cours ainsi comme les conditions pour leur développement. Nous étu- 
dions le cas de la gestion de l'énergie éolienne dans la région du détroit de Gibraltar. Le développement éolien est analysée dans les territoires euro-méditerranéens, par comparaison entre différents États et régions espagnoles par moyen de divers indicateurs. Reconnaissance des principaux pays par leur potentiel et leur politiques visant à promouvoir les alternatives éoliennes.

Mots clé: énergie éolienne, région euro-méditerranéenne, planification énergétique

\section{INTRODUCCIÓN}

Los países ribereños del Mediterráneo, bajo muy distintos sistemas políticos y económicos, participan de condiciones biofísicas comunes, si bien con dominios y matices diferenciados, como consecuencia de su latitud, relativa proximidad, y de compartir una extensa línea de costa. Esto implica ciertas semejanzas climáticas, especialmente en las proximidades del mar, y la presencia de vientos regulares asociados al litoral, a la altitud, a zonas con escaso coeficiente de rugosidad y vegetación, que en conjunción con la disposición espacial del relieve, originan pasillos preferentes en la entrada de las masas de aire, función a su vez, de gradientes regionales de presión atmosférica. Estos vientos, aprovechados históricamente por los antiguos navegantes del Mare Nostrum, constituyen hoy un importante potencial para el aprovechamiento energético, en un entorno marcado por el crecimiento progresivo de las energías renovables.

La energía eólica en España se ha desarrollado intensamente, hasta el punto de ocupar el cuarto puesto mundial en 2010 por capacidad instalada (20.676 MW), sólo precedida por China, Estados Unidos y Alemania (World Wind Energy Association, 2011). Esta situación convierte a España en uno de los candidatos clave para liderar y difundir el desarrollo eólico en el espacio mediterráneo. La región mediterránea ocupa una zona de transición entre dos áreas marcadamente diferentes -la zona templada húmeda y la zona calurosa del desierto- especialmente sensible a los cambios ambientales, y por añadidura, al cambio climático (Regato, 2008). Se trata de una frontera con una alta desigualdad socioeconómica entre los países de la orilla Norte y los del Sur, lo que provoca importantes procesos migratorios hacia Europa, manifiestamente visibles a través de la llegada periódica de embarcaciones "pateras". El Estrecho de Gibraltar es un área singular por sus excepcionales condiciones para el desarrollo de la energía eólica debido al efecto de encajonamiento, y ser punto de unión entre masas de aguas con muy diferentes condiciones físico-térmicas, lo que se traduce en un intenso gradiente de los fluidos atmosféricos y marinos que lo rodean (Ventura Fernández, J. y Moreno Navarro, J.G., 2004). Es un punto de máxima cercanía entre Europa y el Norte de África, que separa los territorios vecinos de España y Marruecos por apenas $15 \mathrm{~km}$. Pese a que la energía eólica es por el momento la fuente no convencional de energía renovable de mayor madurez, y tener un notable potencial en el Mediterráneo, existen pocos estudios que aborden específicamente el desarrollo eólico desde una perspectiva íntegramente euromediterránea, puesto que la mayoría adoptan un enfoque nacional. Destacan, entre otros, el trabajo sobre energía eólica en España de Espejo Marín (2004a), así como los centrados 
en las oportunidades de la integración eléctrica euromediterránea para distintos sectores (Gonzalo Escribano, 2010; Hanelt, 2010), y del Mercado Ibérico de la Electricidad (Espejo Marín, 2004b).

\section{OBJETIVOS}

El objetivo principal de este trabajo es caracterizar en una primera aproximación al desarrollo eólico en la región euromediterránea, identificar proyectos principales en marcha y condicionantes de desarrollo. Pretende además contribuir a responder las siguientes cuestiones: ¿Cuál es el grado de aprovechamiento eólico relativo de los países integrantes y de las comunidades autónomas españolas?, ¿qué iniciativas destacables de desarrollo e integración eólica existen? y ¿qué repercusiones y oportunidades pueden tener para España y el resto de países mediterráneos?.

\section{MÉTODOLOGÍA}

En primer lugar se realiza un estudio de caso del desarrollo y ordenación de la energía eólica en el área del Estrecho de Gibraltar. Se contrasta la planificación eólica a una y otra orilla del Estrecho de Gibraltar. A continuación se define el desarrollo eólico en los territorios euromediterráneos comparando los distintos países y comunidades autónomas españolas mediante diversos indicadores: a saber, potencia eólica instalada, aprovechamiento eólico territorial $\left(\mathrm{Kw}\right.$ por $\left.\mathrm{km}^{2}\right)$, aprovechamiento eólico per cápita (Kw per cápita) e Intensidad de Aprovechamiento Eólico (producto de los dos últimos indicadores). El déficit eólico relativo $\left(\mathrm{Kw} / \mathrm{km}^{2}\right)$ se estima como la diferencia entre la potencia eólica instalada por $\mathrm{km} 2$ y la media ponderada por $\mathrm{km} 2$ de la potencia eólica instalada en los países europeos de la región. Se aporta una aproximación del potencial eólico no valorizado respecto a la media de países europeos mediterráneos, para cada país, y en una y otra orilla de la región, a partir del producto del déficit eólico relativo por la superficie del país. Se caracterizan países clave según su potencial eólico no valorizado, situación, y políticas de fomento eólico. Finalmente, se identifican proyectos estratégicos y condicionantes, a partir del estudio bibliográfico y de noticias de prensa sobre el desarrollo eólico en la región euromediterránea.

\section{RESULTADOS}

\subsection{LA ENERGÍA EÓLICA EN LAS DOS ORILLAS DEL ESTRECHO DE GIBRALTAR}

En 1979 se inició el diseño y la construcción de un aerogenerador para el aprovechamiento de los intensos vientos de la costa de Tarifa (Foncubierta Rodríguez, M.J., 2010). Después de las primeras y exitosas experiencias, se comenzó el proyecto del Parque Eólico del Estrecho, instalándose el primer parque eólico de Andalucía en el municipio de Tarifa en 1992 (Rodríguez, S., 2010). En los inicios de la energía 
eólica en España, el Estrecho de Gibraltar fue la primera zona en desarrollarse, acaparando en torno al $50 \%$ de las instalaciones, como se puede apreciar en la tabla 1.

Tabla 1. Distribución en \% de aerogeneradores y potencia eólica instalada en 1994.

\begin{tabular}{|l|l|l|}
\hline Área & \% de aerogeneradores & \% de potencia instalada \\
\hline Gibraltar & 56 & 46 \\
\hline Islas Canarias & 28 & 34 \\
\hline Galicia & 7 & 7 \\
\hline Aragón & 6 & 8 \\
\hline Navarra & 1 & 4 \\
\hline Cataluña & 1 & 1 \\
\hline
\end{tabular}

Fuente: Fluxá Ceva, J.M. y Gómez Landesa, E. (1995).

El área del Estrecho de Gibraltar destaca por su elevada aptitud eólica, como puede apreciarse en los mapas de la figura 1. El potencial eólico explotable de Marruecos se estima en 6000 MW según el "MED 2010 Project" (citado en ICEX, 2011). Este mismo estudio considera, sólo para el Norte de Marruecos, unos 1.000 MW explotables. Las antiguas provincias de Tánger y de Tetuán, en el entorno del Estrecho de Gibraltar, disponen de un potencial eólico sobresaliente, con velocidades medias anuales de viento entre 8 y $11 \mathrm{~m} / \mathrm{s}$.

Figura 1. Mapas de velocidad media del viento de España y Marruecos (m/s)
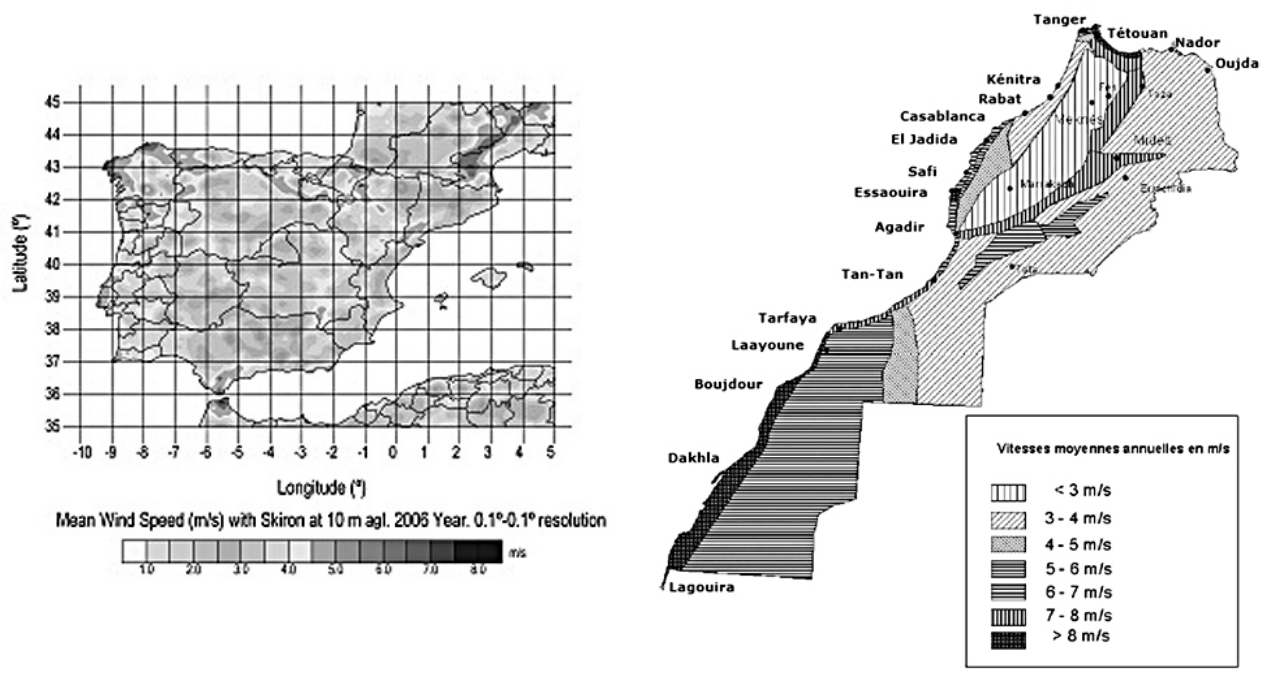

Fuentes: Mapa eólico de España (Gastón M., Pascal E., et al., 2008) y de Marruecos Fritzsche, K., et al. (2011). Datos originales de CDER (2007)

La velocidad y frecuencia de vientos en el mar es de gran interés para la explotación eólica. La profundidad de la costa y la capacidad tecnológica para operar en 
las difíciles condiciones que impone el medio marino son factores limitantes clave. La ordenación eólica marina en España se basa en una zonificación ambiental de áreas costeras que clasifica las diferentes zonas aptas, zonas de exclusión y zonas aptas con condicionantes medioambientales según establece el Estudio Estratégico Ambiental del litoral español para la instalación de parques eólicos marinos (Ministerio de Medio Ambiente y Medio Rural y Marino, 2009). La clasificación de una zona como apta no exime de la realización y aprobación de los ulteriores estudios de impacto ambiental de las instalaciones de energía eólica en el mar. En las zonas de exclusión identificadas se encuentran enclaves de excepcional importancia para la migración de las aves y otros grupos biológicos en torno al área del paso del Estrecho de Gibraltar.

La ordenación de los territorios con especiales condiciones para la implantación de energías renovables es un aspecto de primera importancia en el que el área del Estrecho de Gibraltar también ha sido pionero. Uno de los primeros hitos de ordenación territorial del desarrollo eólico en Andalucía fue el Plan Especial de Ordenación de las instalaciones eólicas de Tarifa (Toscano Benavides, L., 2000). Posteriormente, en 2003, se aprobó el Plan Especial supramunicipal de ordenación de infraestructuras de los recursos eólicos en la comarca de La Janda (Diputación de Cádiz, 2003).

La Ley $2 / 2007$, de fomento de las energías renovables y del ahorro y eficiencia energética de Andalucía, contempla la elaboración de programas territoriales de energías renovables para determinadas zonas. Éstos definirán, cuando proceda, posibles zonas compatibles para infraestructuras de generación y transformación de energías renovables, así como los pasillos necesarios para la evacuación de la energía producida, que se denominarán Áreas Preferentes de Energías Renovables (APER). Además, la planificación territorial y los planes urbanísticos garantizarán, en el marco establecido por los mismos, que en los espacios vinculados a la generación y transporte de energías renovables previstos en las áreas preferentes contenidas en los programas territoriales de energías renovables, tenga prioridad este uso respecto a otros. No obstante, y de forma justificada, la planificación territorial podrá establecer ubicaciones alternativas para estos espacios siempre que se aseguren los objetivos generales de la planificación energética y la coherencia del conjunto.

El Plan de Ordenación del Territorio de la Aglomeración Urbana de la Comarca del Campo de Gibraltar (actualmente en tramitación) señala que existen 55 instalaciones productoras de energía eólica en el ámbito según el Registro del Ministerio de Industria, Turismo y Comercio, con una potencia total instalada de $857.800 \mathrm{Kw}$, el 91\% de la cual se encuentra en el municipio de Tarifa. Este Plan, de ámbito subregional, indica que los instrumentos de planeamiento general, a fin de no condicionar la localización futura de los desarrollos urbanísticos, deberán determinar aquellos suelos que deben ser preservados de la implantación de instalaciones de producción industrial de energía renovable. Asimismo, en la zona que se delimita como zona de exclusión de energías renovables industriales, no se admitirán nuevos proyectos de parques eólicos cuya finalidad sea producir energía eléctrica con destino a su venta en la red eléctrica general. 
Los otros planes territoriales que inciden sobre la ordenación eólica del Campo de Gibraltar son los Planes Rectores de Uso y Gestión (PRUG) de los terrenos situados en los parques naturales presentes. En particular, el PRUG del Parque Natural de Los Alcornocales establece, para los nuevos parques eólicos, que: a) las solicitudes para la construcción de nuevos parques eólicos deberán estar acompañadas, al margen de los requisitos que la normativa vigente aplicable exija, de un estudio anual de los efectos de dicha instalación sobre la avifauna; b) la ubicación de dichas infraestructuras tendrá lugar fuera de un radio de dos kilómetros de las áreas de nidificación de las aves rapaces reproductoras presentes en este espacio y de las principales rutas migratorias de las aves a través del paso del Estrecho; y c) se desarrollarán preferentemente en los lugares cuyas instalaciones existentes hayan quedado obsoletas, o en aquellas áreas fuertemente degradadas y cercanas a las principales vías de comunicación. Los tendidos eléctricos de evacuación de la energía generada en los parques eólicos de nueva instalación deberán ser subterráneos siempre que sea técnica, económica y ambientalmente viable. Una vez que las instalaciones de los parques eólicos existentes queden obsoletas, se procederá a la desinstalación de las mismas y a la restauración paisajística del área que ocupaban. Igualmente, el PRUG del Parque Natural del Estrecho señala que, en los parques eólicos presentes dentro del espacio protegido, queda prohibido el aumento del número y tamaño de aerogeneradores instalados, permitiéndose sólo las actuaciones de reparación, mantenimiento o mejora de infraestructuras eólicas con objeto de minimizar su impacto ambiental. Para la instalación de infraestructuras de transformación de energía eólica con destino al autoconsumo se necesitará una autorización, debiendo quedar plenamente justificada de manera documental su vinculación a explotación agrícola, forestal o ganadera, o, en su caso, a uso turístico y la potencia necesaria para el normal desarrollo de la actividad.

La provincia de Cádiz se caracteriza por el predominio eólico, que supone el $42 \%$ de la potencia eólica instalada en Andalucía. Sin embargo Cádiz, una provincia pionera en la implantación de parques de aerogeneradores no ha desarrollado una verdadera industria eólica (Galdós Urrutia, R.; Madrid Ruiz, F.J., 2009).

En el Estrecho de Gibraltar existen dos "comarcas energéticas" colindantes. Por un lado, la Comarca del Campo de Gibraltar, compuesta por los términos de Tarifa, Algeciras, Jimena de la Frontera, Castellar de la Frontera, San Roque, La Línea de la Concepción y Los Barrios. Por otro, la Comarca de La Janda, integrada por Vejer de la Frontera, Alcalá de los Gazules, Barbate, Benalup-Casas Viejas, Conil de la Frontera, Medina Sidonia y Paterna de Rivera. Se constata la especialización energética de los municipios de estas comarcas muy consolidadas (Cano García, 2002), debiendo diferenciarse aquellos de especialización energética industrial ligados a la concentración industrial de la Bahía de Algeciras, como el municipio de San Roque, de los ligados claramente a los desarrollos eólicos, como el municipio de Tarifa.

Si se compara la potencia eólica instalada de energía eólica en Andalucía y en Marruecos se observa que pese a que el país vecino dispone de recursos eólicos potenciales similares y una extensión que quintuplica la de Andalucía, el desarrollo eólico de Marruecos no llega siquiera al $10 \%$ de la potencia eólica instalada en Andalucía, ni al 23\% de la potencia eólica instalada en la provincia de Cádiz. La evo- 
lución de la potencia eólica instalada que representa la figura 2, positiva tanto en la región andaluza como en el Reino de Marruecos, muestra pendientes mucho mayores en Andalucía, que señalan tasas de crecimiento anual muy superiores en esta Comunidad Autónoma.

Figura 2. Evolución de la potencia eólica instalada de energía eólica en Andalucía y Marruecos (MW)

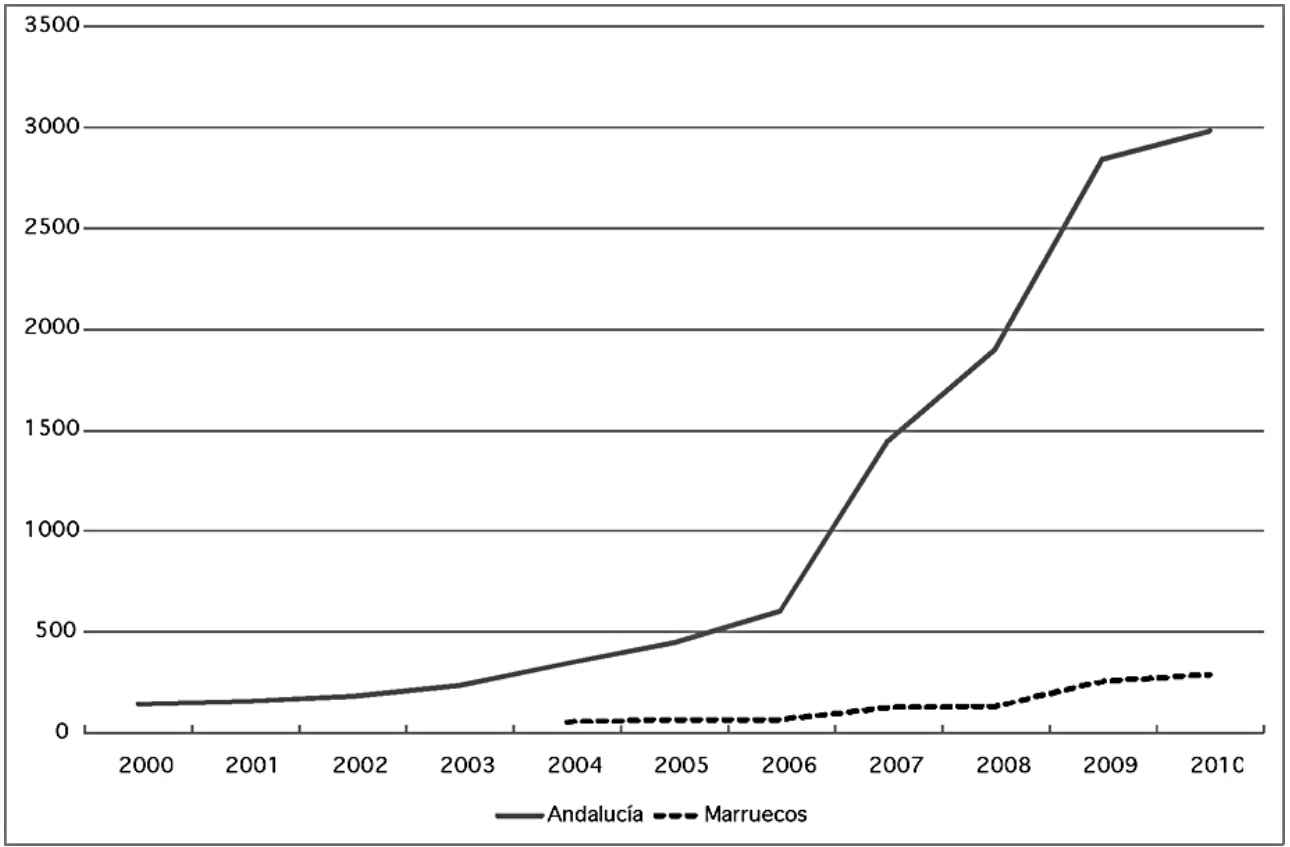

Fuente: Elaboración propia a partir de APREAN (2011) y Global Wind Energy Council (2010)

Según el estudio sobre el sector de la energía eólica en Marruecos publicado por el ICEX en 2011, este país es deficitario en energía e importa de España el 18,1\% del total de la eléctrica demandada a través de la interconexión: 4.621,76 GWh en 2009. Sin embargo, es previsible un cambio de la situación en el panorama de las energías renovables en Marruecos, dada la predisposición gubernamental y el apoyo de organismos de financiación multilateral para aprobar proyectos de reducción de las emisiones de carbono. Recientemente, el Banco Mundial ha asignado 150 millones de dólares a Marruecos para proyectos de este tipo. El Plan Estratégico Nacional de Desarrollo de Energías Renovables lanzado por el CDER estableció entre sus objetivos la instalación de $1.000 \mathrm{MW}$ de parques eólicos para 2012 ("Iniciativa 1000 MW"). Se prevé que supondrá más de 1.800 empleos relacionados con la fabricación local de piezas para aerogeneradores y la instalación de parques eólicos, y empleos relacionados con la explotación y el mantenimiento (1.400), además de 4.500 empleos indirectos (ICEX, 2011). Este mismo estudio afirma que el desarrollo de la energía eólica en Marruecos dependerá de la capacidad para atraer grandes inversores 
extranjeros y crear las condiciones favorables a la inversión, tal como ofrecen países de la región mediterránea como Italia, Francia y España. La tabla 2 pone de manifiesto la importante presencia de las empresas españolas en el desarrollo eólico de Marruecos, especialmente en el Norte del país magrebí.

Tabla 2. Actuaciones y proyectos de energía eólica en el Norte de Marruecos.

\begin{tabular}{|c|c|c|}
\hline \begin{tabular}{c|} 
Actuación \\
\end{tabular} & Empresa o institución & Observaciones \\
\hline $\begin{array}{l}\text { Contrato con la ONE en } 2005 \text { para la } \\
\text { construcción del parque eólico de } \\
\text { Essaouira de } 60 \mathrm{MW} \text { de potencia }\end{array}$ & Gamesa & $\begin{array}{l}\text { Gamesa es la empresa española } \\
\text { de energía eólica con más presen- } \\
\text { cia en Marruecos }\end{array}$ \\
\hline $\begin{array}{l}\text { Contrato con la ONE para el suminis- } \\
\text { tro de } 165 \text { turbinas eólicas para el par- } \\
\text { que eólico de Tánger }\end{array}$ & Gamesa & $\begin{array}{l}\text { Es la mayor instalación eólica del } \\
\text { país magrebí. }\end{array}$ \\
\hline $\begin{array}{l}\text { Contratos de nuevos aerogeneradores } \\
\text { a Cementos Lafarge: } 3^{\mathrm{a}} \text { fase de par- } \\
\text { que eólico en Tetuán }\end{array}$ & Gamesa & $\begin{array}{l}\text { Gamesa ya había participado en } \\
\text { fases anteriores en este parque. }\end{array}$ \\
\hline $\begin{array}{l}\text { Instalaciones eléctricas del parque } \\
\text { eólico de Tánger }\end{array}$ & Global Energy Services (GES) & Empresa española. \\
\hline $\begin{array}{l}\text { Proyecto Morena (sistema híbrido eóli- } \\
\text { co, fotovoltaico y diesel) en Ouassen. }\end{array}$ & $\begin{array}{l}\text { Instituto Tecnológico de } \\
\text { Canarias (ITC) }\end{array}$ & $\begin{array}{l}\text { Se trata de una entidad depen- } \\
\text { diente del Gobierno de Canarias. }\end{array}$ \\
\hline $\begin{array}{l}\text { Estudio de viabilidad financiado con } \\
\text { cargo al FEV sobre el impacto de las } \\
\text { Energías Renovables sobre la red eléc- } \\
\text { trica marroquí en el horizonte } 2010 .\end{array}$ & Red Eléctrica Española (REE) & $\begin{array}{l}\text { Se está llevando a cabo la amplia- } \\
\text { ción de este estudio para } 2015 .\end{array}$ \\
\hline $\begin{array}{l}\text { Contrato con Nareva Holding, para } \\
\text { construir el parque eólico en Akhfenir. }\end{array}$ & Alston España & \\
\hline $\begin{array}{l}\text { Parque eólico de Abdelkhalek Torres, } \\
\text { a } 40 \text { kilómetros de Tetuán; }\end{array}$ & ONE & $\begin{array}{l}\text { Operativo desde el año } 2000 \text {. La } \\
\text { producción media anual es de } 226 \\
\text { GWh, }\end{array}$ \\
\hline $\begin{array}{l}\text { Concurso de la ONE en } 2007 \text { del } \\
\text { Proyecto "Morocco } 1000 \text { MW Wind } \\
\text { Farm Project". }\end{array}$ & $\begin{array}{l}\text { Barlovento Recursos } \\
\text { Naturales }\end{array}$ & Empresa riojana \\
\hline
\end{tabular}

Fuente: Elaboración propia a partir de ICEX (2011).

El Plan de Acción Nacional de Energías Renovables de España (PANER) 20112020 establece un objetivo nacional de un $20 \%$ para la cuota de energía procedente de fuentes renovables en el consumo de energía final bruta en 2020. Recoge dos grandes bloques de actuaciones con relevancia para el área del Estrecho de Gibraltar: 1) tratamiento administrativo diferenciado para la repotenciación de parques eólicos mediante la sustitución parcial o total de sus aerogeneradores, que facilite las gestiones administrativas necesarias, aunque hasta la fecha sólo se han repotenciado instalaciones eólicas puntuales en Canarias y Cádiz; y 2) se plantea como hipótesis una posible capacidad de intercambio Marruecos-España de 2000 MW gracias a nuevos refuerzos, aún pendientes de definir. En este caso, el límite a la capacidad de tránsito Marruecos - Unión Europea (a través de España y Francia) estará limitada por el potencial de intercambio en el sentido España-Francia, que se podrá incrementar con nuevas interconexiones. 
El PANER fija los siguientes objetivos para 2020: a) 35.000 MW de eólica en tierra: 34.630 MW en media y gran potencia, incluyendo la repotenciación de los parques eólicos obsoletos, y $370 \mathrm{MW}$ de pequeña potencia; y b) $3.000 \mathrm{MW}$ de eólica marina ("off shore"). La figura 3 refleja la potencia eólica previsible de acuerdo con las planificaciones energéticas correspondientes al contexto español, andaluz y marroquí. La potencia eólica a instalar según el objetivo marcado por el PANER es muy importante. El proyecto marroquí de energía eólica pretende alcanzar los 2000 MW para el 2020, lo que implica un significativo esfuerzo inversor considerando el nivel de base del que se parte.

Figura 3. Potencia eólica prevista en las planificaciones energéticas en España, Andalucía y Marruecos

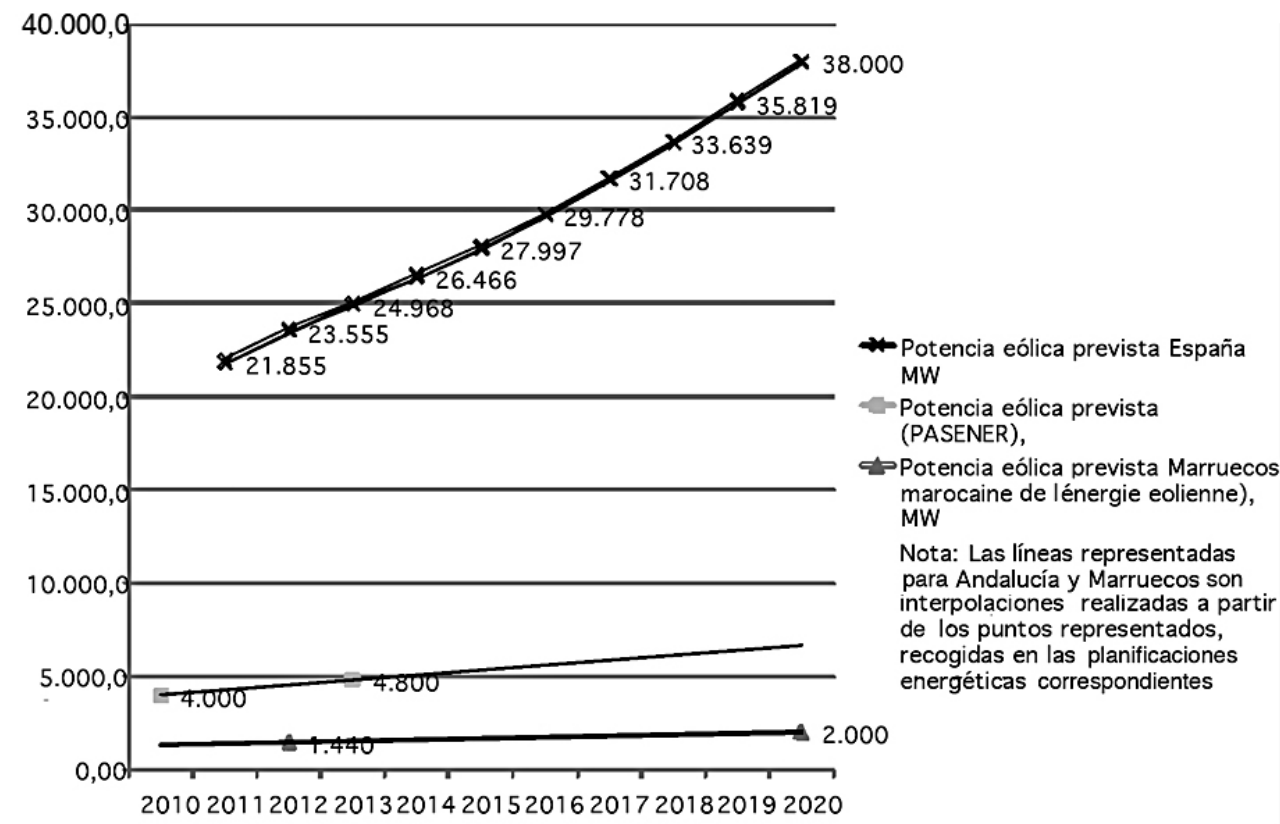

Fuente: Elaboración propia a partir de Plan de Acción Nacional de Energías Renovables de España (PANER) 2011-2020, Plan Andaluz de Sostenibilidad Energética 2007-2013 (PASENER) y Project marocaine de l'énergie eolienne (Office National de 1'Electricité, 2010)

\subsection{EL DESARROLLO EÓLICO EN TERRITORIOS MEDITERRÁNEOS}

El desarrollo eólico mediterráneo es liderado en términos absolutos con diferencia por España, seguido de Italia, Francia y Portugal (figura 4). Prueba de ello es que comunidades autónomas españolas como Castilla-León tengan potencias eólicas instaladas equivalentes a las de Italia y Francia, o que la provincia de Cádiz supere a la potencia instalada en un país como Grecia. Al comparar el desarrollo eólico mediterráneo en términos relativos (tabla 3), mediante indicadores relacionados con el aprovechamiento eólico, se obtienen resultados que corroboran la hegemonía española.

Considerando el aprovechamiento eólico por unidad territorial ( $\mathrm{Kw}$ por $\mathrm{km} 2)$, obtienen los primeros puestos la provincia de Cádiz, Galicia y Navarra, en sintonía 
con los resultados de la tabla 1, donde se mostraba la potencia eólica instalada en 1994. Sin embargo, se aprecia cierta divergencia para la comunidad canaria, también pionera, y con una favorable presencia de vientos alisios, caracterizada asimismo por condiciones de alta densidad poblacional y de espacios naturales protegidos. España encabeza el aprovechamiento eólico territorial, seguido de cerca por Portugal. A continuación se sitúa Italia, y, a cierta distancia, Francia y Grecia. En el contexto árabe destaca en primer lugar Turquía, seguido de Marruecos y Egipto. Llama la atención la inexistencia de aprovechamientos eólicos en Algeria y Libia, en los Balcanes y en las comunidades autónomas de Madrid y Extremadura.

Figura 4. Potencia eólica instalada (MW) en la región euromediterránea (2010)

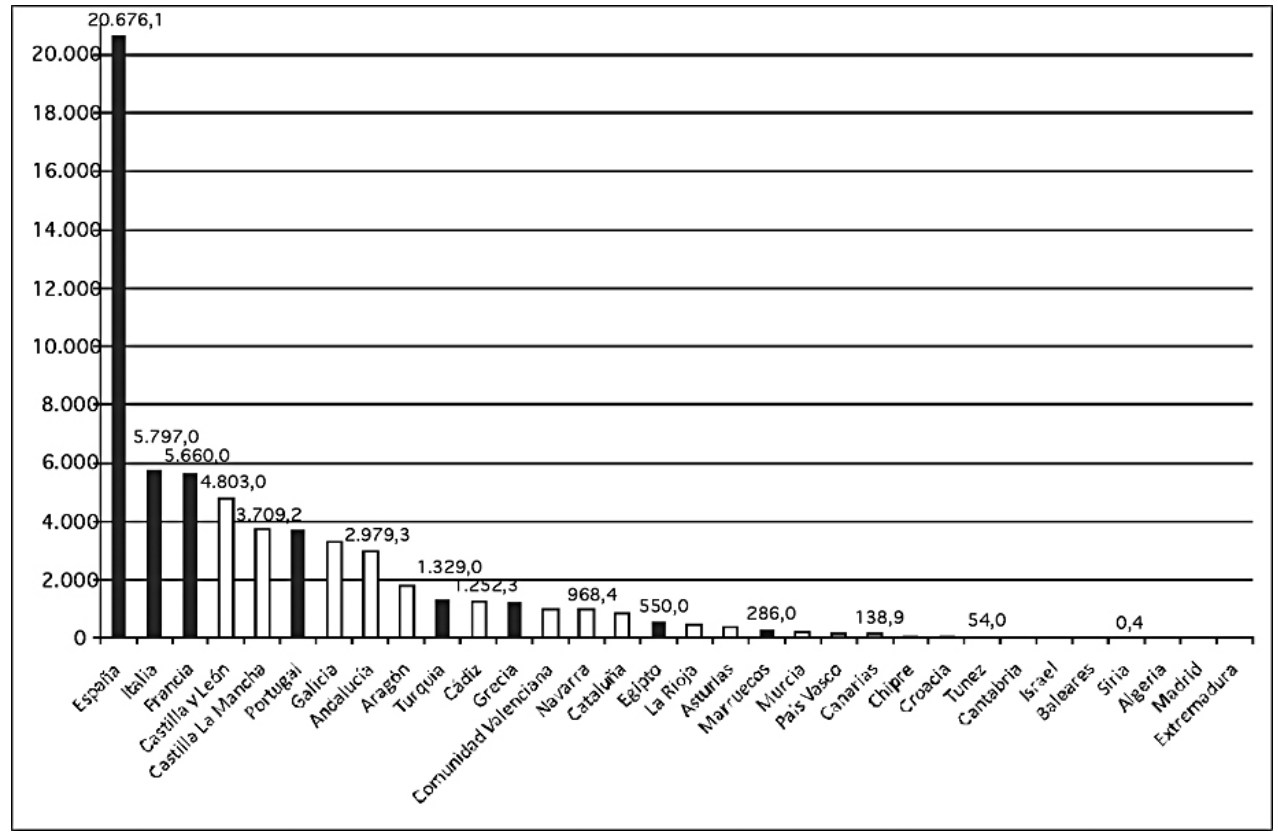

Fuente: Elaboración propia a partir de World Wind Energy Association (2011) y APREAN (2011). Nota: la potencia instalada de los países se representa en oscuro; en claro las comunidades autónomas españolas, y la provincia andaluza de Cádiz

El ranking del indicador Intensidad de Aprovechamiento Eólico, producto del aprovechamiento eólico territorial y del aprovechamiento eólico per cápita, es liderado igualmente por el mediterráneo occidental: España, Portugal e Italia, y por Turquía, seguido de Marruecos y Egipto en el bloque mediterráneo árabe. La tabla 4 muestra una estimación del déficit eólico relativo, expresado en $\mathrm{Kw} / \mathrm{km}^{2}$ y una aproximación relativa al potencial eólico no valorizado respecto a la media de los países europeos mediterráneos. Se aprecia que los países, ordenados por la magnitud del referido potencial eólico no valorizado, es el siguiente. En primer lugar, aparecen Argelia y Libia, ambas potencias exportadoras de combustibles fósiles. En segundo lugar les siguen Egipto y Turquía: el primero un país exportador de gas con explota- 
ciones en declive, y el segundo con gran dependencia energética del exterior. En tercer lugar se sitúan Marruecos y Francia, caracterizados, respectivamente, por su alto déficit energético, así como por la producción eléctrica nuclear gala.

Tabla 3. Ranking en el indicador Intensidad de Aprovechamiento Eólico de países mediterráneos y comunidades autónomas españolas (2010).

\begin{tabular}{|c|c|c|c|c|}
\hline & $\begin{array}{l}\text { Potencia eólica } \\
\text { instalada (MW) } \\
2010\end{array}$ & $\begin{array}{l}\text { Aprovechamiento } \\
\text { eólico territorial } \\
\left(\mathrm{Kw} \text { por } \mathrm{km}^{2}\right)(\mathrm{a})\end{array}$ & $\begin{array}{l}\text { Aprovechamiento } \\
\text { eólico per cápita } \\
\text { (Kw per cápita) (b) }\end{array}$ & $\begin{array}{l}\text { Ranking de } \\
\text { Intensidad de } \\
\text { Aprovechamiento } \\
\text { Eólico. (a) x (b) }\end{array}$ \\
\hline Cádiz (provincia) & $1.252,3$ & 168,41 & 1,01 & 170,52 \\
\hline Navarra & 968,4 & 93,20 & 1,52 & 141,70 \\
\hline Galicia & $3.289,3$ & 111,22 & 1,18 & 130,77 \\
\hline La Rioja & 446,6 & 88,52 & 1,39 & 122,62 \\
\hline Castilla y León & $4.803,0$ & 50,97 & 1,88 & 95,65 \\
\hline Castilla La Mancha & $3.709,2$ & 46,68 & 1,77 & 82,51 \\
\hline Aragón & $1.764,0$ & 36,97 & 1,31 & 48,41 \\
\hline España & $20.676,1$ & 40,91 & 0,45 & 18,36 \\
\hline Portugal & $3.702,0$ & 40,20 & 0,35 & 13,99 \\
\hline Andalucía & $2.979,3$ & 34,01 & 0,36 & 12,11 \\
\hline Asturias & 356,0 & 33,57 & 0,33 & 11,02 \\
\hline Comunidad Valenciana & 987,0 & 42,44 & 0,19 & 8,20 \\
\hline Cataluña & 851,4 & 26,51 & 0,11 & 3,00 \\
\hline Murcia & 189,9 & 16,79 & 0,13 & 2,18 \\
\hline Italia & $5.797,0$ & 19,24 & 0,10 & 1,84 \\
\hline País Vasco & 153,3 & 21,20 & 0,07 & 1,49 \\
\hline Canarias & 138,9 & 18,65 & 0,07 & 1,22 \\
\hline Grecia & $1.208,0$ & 9,15 & 0,11 & 0,98 \\
\hline Francia & $5.660,0$ & 10,31 & 0,09 & 0,93 \\
\hline Chipre & 82,0 & 8,86 & 0,10 & 0,90 \\
\hline Cantabria & 35,3 & 6,63 & 0,06 & 0,40 \\
\hline Turquía & $1.329,0$ & 1,70 & 0,02 & 0,03 \\
\hline Croacia & 69,8 & 1,23 & 0,02 & 0,02 \\
\hline Marruecos & 286,0 & 0,64 & 0,01 & 0,01 \\
\hline Egipto & 550,0 & 0,55 & 0,01 & 0,00 \\
\hline Baleares & 3,7 & 0,73 & 0,00 & 0,00 \\
\hline Túnez & 54,0 & 0,33 & 0,01 & 0,00 \\
\hline Israel & 6,0 & 0,27 & 0,00 & 0,00 \\
\hline Siria & 0,4 & 0,00 & 0,00 & 0,00 \\
\hline Argelia & 0,1 & 0,00 & 0,00 & 0,00 \\
\hline Libia & 0 & 0 & 0 & 0 \\
\hline Líbano & 0 & 0 & 0 & 0 \\
\hline Bosnia-Herzegovina & 0 & 0 & 0 & 0 \\
\hline Montenegro & 0 & 0 & 0 & 0 \\
\hline Albania & 0 & 0 & 0 & 0 \\
\hline Madrid & 0 & 0 & 0 & 0 \\
\hline Extremadura & 0 & 0 & 0 & 0 \\
\hline
\end{tabular}

Fuente: Elaboración propia a partir de datos de potencia eólica instalada de World Wind Energy Association (2011) y APREAN (2011). Datos de superficie: FAO (países) e INE (España). Estados soberanos en negrilla. 
Argelia dispone de un $50 \%$ de su territorio con velocidades medias de viento considerables, sobre todo en el Suroeste, donde se superan velocidades de $6 \mathrm{~m} / \mathrm{s}$ (Boudghene Stambouli, A., 2011). En conjunto, la potencia eólica no valorizada en países mediterráneos del Magreb, Oriente Medio y Turquía, respecto a la media de los países europeos mediterráneos se estima en 142.296 MW. Dado que Argelia es la nación más extensa de la cuenca mediterránea, con más de $2.300 .00 \mathrm{~km}^{2}$, su potencial eólico es de gran magnitud.

El crecimiento demográfico es elevado en el Magreb, Oriente Medio y Turquía, destacando Libia, Argelia y Egipto, lo que conlleva fuertes demandas energéticas. En contraposición, los países europeos presentan un menor crecimiento demográfico, pero mayores superficies con espacios naturales protegidos y densidad poblacional, que pueden condicionar algunos desarrollos eólicos. Otro aspecto a tener en cuenta son los limitados recursos para la generación hidroeléctrica de los territorios mediterráneos, a causa de la irregularidad y escasez de las precipitaciones.

Atendiendo al origen de sus importaciones energéticas (Reaccess-UNED, 2009), Francia se clasifica en el denominado perfil 2, con un predominio de las importaciones intra-europeas ( $44 \%$ de media), pero elevadas importaciones de Rusia y Asia Central (41\% de media), y moderada contribución de Oriente Medio (6\%) y África del Norte (5\%). Por el contrario, España, Portugal, Italia, Grecia y Chipre se incluyen en el perfil 4, caracterizados por una reducida participación de importaciones intra-europea ( $22 \%$ de media), y un elevado peso de Oriente Medio (27\%), África del Norte (17\%) y África sub-sahariana (8\%). Se constata, pues, el comportamiento claramente diferencial de Francia, que unido a su predominancia energética nuclear, repercute en un desarrollo eólico inferior a su potencial.

La electricidad de fuentes renovables es más cara que la procedente de fuentes convencionales, salvo la energía eólica en emplazamientos muy aptos, en parte debido a los subsidios, explícitos e implícitos, de la energía de origen fósil y nuclear (Pwc-Pricewaterhouse Coopers, 2010); además los subsidios al precio de la energía en el Norte de África son uno de los mayores gastos de los gobiernos y un elemento distorsionador para la entrada de energías renovables. Esto lleva a pensar en el equilibrio de fuerzas en la competitividad de las diferentes formas de energías. La disponibilidad de energía barata por dotaciones abundantes de recursos como los combustibles fósiles en Libia y Argelia, o la prevalencia de la producción eléctrica nuclear en Francia, puede condicionar el desarrollo de energías renovables como la eólica. 
Tabla 4. Indicadores de aprovechamiento eólico en países mediterráneos, déficit eólico y potencial eólico estimado no valorizado (2010).

\begin{tabular}{|c|c|c|c|c|c|c|c|c|c|}
\hline & $\begin{array}{l}\text { Potencia } \\
\text { eólica } \\
\text { instala- } \\
\text { da } \\
(\mathrm{MW}) \\
2010\end{array}$ & $\begin{array}{l}\text { Ratio } \\
\text { pobla- } \\
\text { ción } \\
2015 / \\
2010\end{array}$ & $\begin{array}{l}\text { Importac } \\
\text { ión neta } \\
\text { de ener- } \\
\text { gía (\% } \\
\text { de ener- } \\
\text { gía con- } \\
\text { sumida) }\end{array}$ & $\begin{array}{l}\text { Áreas } \\
\text { protegi- } \\
\text { das } \\
\text { terrestres } \\
(\%, \\
2006)\end{array}$ & $\begin{array}{l}\text { Electrici } \\
\text { d. com- } \\
\text { bust.fósi- } \\
\text { les }(\%)\end{array}$ & $\begin{array}{l}\text { Electrici } \\
\text { dad } \\
\text { hidrául. } \\
(\%)\end{array}$ & $\begin{array}{l}\text { Electrici } \\
\text { dad } \\
\text { nuclear } \\
(\%)\end{array}$ & $\begin{array}{l}\text { Déficit } \\
\text { eólico } \\
\text { relati- } \\
\text { vo,(Kw/ } \\
\text { km2). (a) }\end{array}$ & $\begin{array}{l}\text { Potencial } \\
\text { eólico no } \\
\text { valoriza- } \\
\text { do res- } \\
\text { pecto a } \\
\text { media de } \\
\text { países } \\
\text { europeos } \\
\text { medite- } \\
\text { rráneos } \\
\text { (MW) }\end{array}$ \\
\hline Marruecos & 286 & 1,04 & 95 & 0,8 & 93 & 6 & 0 & $-20,74$ & -9.261 \\
\hline Egipto & 550 & 1,10 & -22 & 4,1 & 87 & 12 & 0 & $-20,83$ & -20.861 \\
\hline Turquía & 1.329 & 1,06 & 73 & 0,6 & 81 & 19 & 0 & $-19,68$ & -15.424 \\
\hline Túnez & 54 & 1,05 & 11 & 0,2 & 99 & 0 & 0 & $-21,05$ & -3.444 \\
\hline Argelia & 0,1 & 1,08 & -346 & 5,1 & 99 & 1 & 0 & $-21,38$ & -50.922 \\
\hline Israel & 6 & 1,12 & 88 & 10,5 & 100 & 0 & 0 & $-21,11$ & -466 \\
\hline Siria & 0,4 & 1,02 & -24 & - & 91 & 9 & 0 & $-21,38$ & -3.959 \\
\hline Libia & 0 & 1,10 & -470 & 0,1 & 100 & 0 & 0 & $-21,38$ & -37.960 \\
\hline España & 20.676 & 1,01 & 79 & 7,9 & 35 & 13 & 21 & 19,53 & \\
\hline Francia & 5.660 & 1,02 & 49 & 10,2 & 10 & 10 & 78 & $-11,07$ & -6.082 \\
\hline Portugal & 3.702 & 1,01 & 82 & 5,1 & 64 & 22 & 0 & $18,82-$ & \\
\hline Italia & 5.797 & 1,03 & 85 & 4,5 & 83 & 11 & 0 & $-2,14$ & $\mid-646$ \\
\hline Grecia & 1.208 & 1,00 & 62 & 1,9 & 92 & 4 & 0 & $-12,23$ & -1.613 \\
\hline Chipre & 82 & 1,09 & 97 & 7,7 & 99,9 & 0 & 0 & $-12,52$ & -116 \\
\hline Croacia & 69,8 & - & - & 5,9 & - & - & - & $-20,15$ & -1.140 \\
\hline $\begin{array}{l}\text { Bosnia } \\
\text { Herzegovina }\end{array}$ & 0 & - & - & 0,5 & - & - & - & $-21,38$ & -1.095 \\
\hline Montenegro & 0 & - & - & 2,9 & - & - & - & $-21,38$ & -295 \\
\hline Albania & 0 & - & - & 0,7 & - & - & - & $-21,38$ & -615 \\
\hline TOTAL & 39.420 & & - & - & - & - & - & - & - \\
\hline \multicolumn{4}{|c|}{$\begin{array}{l}\text { Media ponderada potencia eólica ins- } \\
\text { talada euromediterránea (MW) }\end{array}$} & \multicolumn{5}{|c|}{\begin{tabular}{l|l}
2.064 & $\begin{array}{l}\text { Total potencia eólica instalada países } \\
\text { europeos mediterráneos (MW) }\end{array}$
\end{tabular}} & 37.195 \\
\hline \multicolumn{4}{|c|}{$\begin{array}{l}\text { Media ponderada potencia eólica ins- } \\
\text { talada países europeos mediterráneos } \\
\text { (MW) }\end{array}$} & $1.860 \mid \begin{array}{l}T \\
m \\
M\end{array}$ & \multicolumn{4}{|c|}{$\begin{array}{l}\text { Total potencia eólica instalada paises } \\
\text { mediterráneos del Magreb, Oriente } \\
\text { Medio y Turquía (MW) }\end{array}$} & 2.226 \\
\hline \multicolumn{4}{|c|}{$\begin{array}{l}\text { Media ponderada potencia eólica ins- } \\
\text { talada países mediterráneos del } \\
\text { Magreb, Oriente Medio y Turquía } \\
(M W)\end{array}$} & $203 \mid \begin{array}{l}T \\
p \\
O \\
m\end{array}$ & \multicolumn{4}{|c|}{\begin{tabular}{|l|} 
Total potencia eólica no valorizada en \\
países mediterráneos del Magreb, \\
Oriente Medio y Turquía, respecto la \\
media de países europeos mediterráneos
\end{tabular}} & -142.296 \\
\hline
\end{tabular}

Fuente: Elaboración propia a partir de datos de potencia eólica instalada de World Wind Energy Association (2011) y APREAN (2011). Medias ponderadas por superficie. Población 2015, importación neta de energía y \% de electricidad producida: Banco Mundial-FMI (www.tradingeconomics.com). Datos de \% de electricidad producida de España: Red Eléctrica de España (2010). Áreas protegidas terrestres: World Resource Institute (www.wri.org). Accesos en diciembre 2010. (a): media ponderada países europeos mediterráneos $=21,38 \mathrm{Kw} / \mathrm{km}^{2}$. Déficit eólico relativo $=$ Aprovechamiento eólico territorial país $\left(\mathrm{Kw}\right.$ por $\left.\mathrm{km}^{2}\right)-21,38 \mathrm{Kw}$ por $\mathrm{km}^{2}$. 


\subsection{PERSPECTIVAS}

Las perspectivas de desarrollo eólico en el espacio euromediterráneo están condicionadas por un conjunto de factores interrelacionados. Por un lado, el marco regulatorio de lucha contra el cambio climático, la legislación en materia de primas y subsidios energéticos y a la energía eólica, y las políticas de planificación energética. Aunque se esperan crecimientos eólicos significativos en Europa, y a medio plazo en el Norte de África (World Wind Energy Association, 2011), la capacidad de los distintos gobiernos para trabajar colaborativamente y crear unas reglas comunes aceptadas en el espacio euromediterráneo será crucial. Por otro lado, el Norte tiene que desempeñar un triple papel en los esfuerzos por posibilitar un desarrollo sostenible del Sur, como fuente continua de tecnologías de vanguardia comercial, como fuente de asistencia técnica y financiación innovadora para animar y ayudar a la utilización de estas tecnologías en el Sur, y como ejemplo, adoptando estas mismas tecnologías de modo que se instalen y se demuestre su viabilidad (Strong, M. 1992). Para ello es necesario crear y fortalecer estructuras con proyectos comunes energéticos, catalizadores a su vez de otros procesos de colaboración en el plano político, económico y social.

La anticipación suficiente para planificar e implantar modelos energéticos sostenibles es clave en los países mediterráneos. Los dilatados tiempos necesarios para implantar un modelo energético menos dependiente de fuentes fósiles, la vulnerabilidad ante el cambio climático y el rápido crecimiento demográfico y económico de la orilla Sur mediterránea exigen una respuesta comprometida, rápida y concreta. El uso de fuentes energéticas como la leña en el Magreb deforesta extensas superficies en zonas rurales, que originan procesos de erosión, éxodo rural y migraciones. El desarrollo eólico ordenado puede contribuir a mitigar estos procesos, y actuar a largo plazo como puntos de difusión y demostración hacia el África Subsahariana, dada la probada vinculación entre desarrollo económico y energético.

Pero no se puede crecer eólicamente sin adecuar las interconexiones eléctricas. Marruecos es atravesado por el gasoducto Magreb-Europa, y las interconexiones de las redes eléctricas con España y Argelia son un eslabón decisivo del proyecto de integración progresiva de los mercados eléctricos y de gas de los países magrebíes con el mercado interior europeo (ICEX, 2011). Por consiguiente, las planificaciones energéticas nacionales, a una y otra orilla, deben contemplarse como piezas a integrar de forma concatenada en el contexto del gran puzle territorial euromediterráneo. El ejemplo de China, la primera potencia eólica actual, es ilustrativo. De sus 44.733 MW instalados, sólo 31.070 MW están conectados a la red nacional china, permaneciendo a la espera de conexión un importante número de parques eólicos (World Wind Energy Association, 2011).

Las opciones de desarrollo dependen del clima económico y geopolítico internacional y de los avances diferenciales entre las distintas tecnologías energéticas. La energía eólica se percibe como una fuente de energía renovable de relativa madurez y menor riesgo en escenarios de incertidumbre económica (UNEP, 2010). La noticia del accidente nuclear de Fukushima en Japón incrementará posiblemente el rechazo social hacia la energía nuclear. De hecho, en Alemania la demanda de electricidad 
"verde" ha crecido tras el accidente japonés (Desertec, 2011). Así todo, la participación nuclear es una opción barajada en el panorama energético futuro de algunos países, en un contexto de creciente demanda energética, suministro de energía "barata" con el actual sistema de precios, y de lucha frente al cambio climático. De este modo, Turquía ha anunciado la reapertura del programa de energía nuclear (Yüksel, I., 2008), y prevé la puesta en funcionamiento de una central nuclear de $900 \mathrm{MW}$ para el 2019, con el fin de evitar los frecuentes cortes en el suministro eléctrico (Medlognews, 2010a). Esta misma fuente señala que también ha influido el agotamiento del gas y del petróleo, que obligan a buscar fuentes energéticas alternativas, y que el Gobierno colaborará con la Agencia de Energía Atómica Internacional para demostrar que las instalaciones no están vinculadas con el desarrollo de armas nucleares. Por tanto, hasta los países con recursos energéticos fósiles han de estar preparados para la transición gradual hacia modelos más sostenibles, dada la naturaleza agotable de éstos. En esta línea, Marktanner y Salman (2011) defienden la estrategia del desarrollo preferente de las energías renovables frente a la energía nuclear en el Norte de África por motivos fundamentalmente geopolíticos y de sostenibilidad.

La Directiva 2009/28/CE, de 23 de abril, relativa al fomento de las energías procedentes de fuentes renovables, establece para el año 2020 una cuota global para la Unión Europea del $20 \%$ de energías renovables en el consumo final bruto de energía, que implicará efectos en cascada en las distintas escalas nacionales, regionales y locales. El artículo 9 dispone que la electricidad producida a partir de fuentes de energía renovables en terceros países únicamente se tendrá en cuenta para evaluar el cumplimiento de los requisitos de la Directiva en relación con los objetivos globales nacionales si la electricidad se consume en la Comunidad, condición que se considerará cumplida cuando, entre otras, una cantidad de electricidad equivalente a la electricidad considerada haya sido asignada definitivamente a la capacidad de interconexión atribuida por todos los gestores de la red de transporte del país de origen, del país de destino y, en su caso, de cada uno de los terceros países de tránsito. Se supedita, en consecuencia, a la capacidad de evacuación de la red eléctrica internacional en la cuenca mediterránea.

La energía eólica es un tipo de energía renovable muy variable. Capaz de cubrir en determinados momentos una importante parte de la demanda, en situaciones de fuerte eolicidad, impone ciertas limitaciones de producción durante algunas horas de demanda valle, y disponer de infraestructuras adecuadas de evacuación de la energía producida. El anillo energético euromediterráneo está incompleto por el momento, como muestra la figura 5. El tándem energía eólica-interconexiones-capacidad suficiente de las redes eléctricas es prácticamente ineludible. En países montañosos con lluvias abundantes una alternativa es el almacenamiento energético mediante bombeo hidráulico hacia presas en los momentos de excedentes de la producción eólica. Sin embargo, esta posibilidad es poco aplicable a gran escala en el mediterráneo meridional, siendo una excepción Marruecos, debido a su carácter montañoso y mejores dotaciones hídricas. No obstante, la interconexión a una gran red eléctrica internacional minimiza el problema del almacenamiento de la energía eléctrica, al poder jugar con un gran número de conexiones y centros de consumo en la evacuación. 
Figura 5. Intercambios anuales de energía $(\mathrm{GWh}, 2008)$ y fragmentación de interconexiones en el Mediterráneo

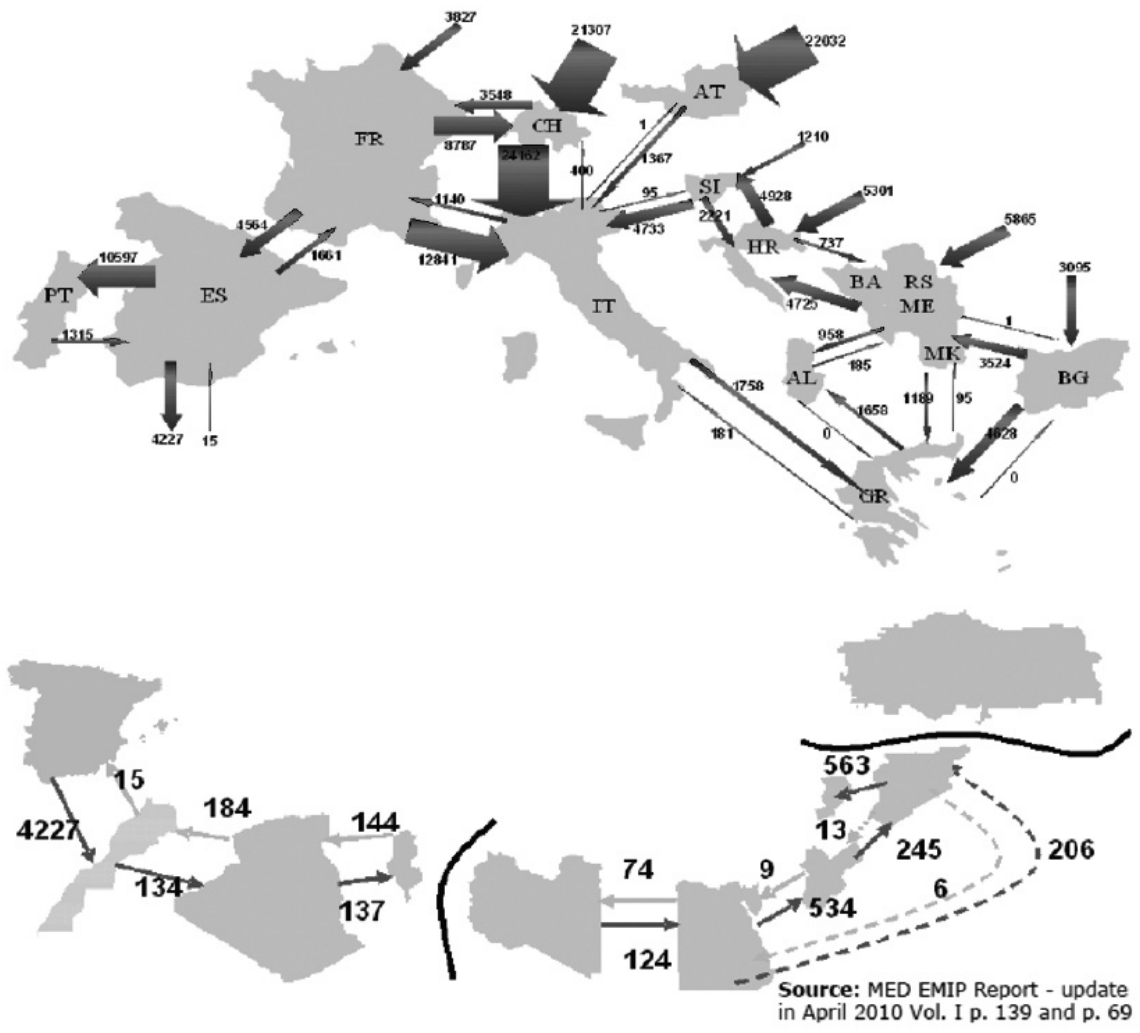

Fuente: European Parliament (2011)

En el espacio euromediterráneo España, Marruecos, Egipto y Turquía son países claves en el desarrollo eólico. Los dos primeros articulan la conexión Norte-Sur en el mediterráneo occidental, y los segundos con Europa y Oriente Medio. Poseen una alta aptitud eólica, extensa línea de costa, cuentan con un grado de desarrollo eólico significativo, y con políticas favorables a la promoción eólica. Además, Marruecos, Egipto y Turquía disponen de un alto potencial eólico no valorizado en comparación con la media de los países europeos mediterráneos, tal como se expuso con anterioridad. Marruecos ha anunciado un objetivo del $42 \%$ de contribución de las energías renovables para 2020; Argelia ha fijado para el año 2030 que el $20 \%$ de su generación eléctrica proceda de fuentes de energía renovables; y Túnez tiene como objetivo quintuplicar la contribución de las energías renovables en el consumo total de energía (Medlognews, 2011b). El Banco Mundial ha adjudicado un crédito de 220 millones de dólares al operador de la red egipcio, destinados a la construcción de infraestructuras para la evacuación de energía eólica de la región de Gabal el-Zeit, donde el Gobierno Central planifica la instalación de $2.500 \mathrm{MW}$ eólicos en los próximos años (Expansión, 2010). Por otra parte, el Gobierno de Egipto ha 
anunciado un plan que pretende elevar la producción de electricidad a través de energías alternativas hasta un 20\% para 2012. Por su parte, Argelia, Túnez y Egipto han comenzado programas para reducir los subsidios y ajustar los precios de la energía a niveles internacionales (Pwc-Pricewaterhouse Coopers, 2010). El gobierno turco ha decidido prorrogar su Ley de Energías Renovables hasta el año 2013, lo que "aporta visibilidad más allá de 2010, el año de vencimiento inicialmente establecido", según reconocía un promotor español activo en el país. La tarifa está garantizada durante los primeros dos años de operación de los parques eólicos. De este modo, el gobierno turco prevé 16.000 millones de euros en licencias para impulsar energías renovables (eólica y solar) en los próximos cuatro años (Medlognews, 2010b). La multinacional española Gestamp, ha comenzado a construir su nueva planta de fabricación de torres eólicas en Turquía, para poder suministrar eficientemente al mercado local y de igual manera exportar a los importantes mercados vecinos de Rumanía, Bulgaria y Grecia, que están experimentado un fuerte desarrollo del mercado eólico en estos últimos años (Medlognews, 2010c).

Parejo al desarrollo eólico de la región, la financiación de los bancos mediterráneos es fundamental, a la vez que una oportunidad de negocio. De hecho, cinco entidades financieras europeas, Caisse de Dépôts, la Agencia Francesa de Desarrollo (AFD), el Banco Europeo de Inversiones (BEI), Cassa Depositi e Prestiti (CDP), y KfW Bankengruppe, han decidido seguir los pasos del primer fondo de inversión en infraestructuras en el Mediterráneo (InfraMed Infraestructure Fund), y han iniciado los preparativos para crear el primer fondo de inversión en proyectos sostenibles en el Mediterráneo. El fondo, que ha sido bautizado como Mediterranean Carbon Fund, se enmarca dentro de la Unión por el Mediterráneo, y responde al primero de sus ejes prioritarios, que busca luchar contra los efectos del cambio climático en la región (Medlognews, 2011c). El fondo aportará la experiencia de sus miembros y una ayuda financiera adicional para proyectos en marcha en el Sur y Este del Mediterráneo. El fondo se basa en los créditos generados por el Mecanismo de Desarrollo Limpio (MDL), un instrumento previsto en el Protocolo de Kyoto para cumplir los objetivos de reducción de gases de efecto invernadero invirtiendo en proyectos sostenibles en países en desarrollo, como alternativa para adquirir reducciones certificadas de emisiones. La opción de realizar MDL en el espacio mediterráneo tiene la ventaja de apoyar la Política Europea de Vecindad, y de conectar físicamente el propio sistema energético nacional y europeo del país inversor con el del país en vías de desarrollo, opción prácticamente inviable en continentes o regiones muy distantes, como por ejemplo, América. Adicionalmente, la densidad de áreas naturales protegidas y de población es inferior al Sur del Mediterráneo, y el consiguiente desarrollo de los países vecinos revertiría en una y otra orilla. Ello no obsta para aplicar con uniformidad en la región criterios rigurosos, medioambientales y tecnológicos, tanto en la fase de planificación como de explotación eólica. Los costes de seguimiento ambiental son inherentes a los desarrollos eólicos, y oscilan entre 24.000-125.000 € al año (Endesa-Escuela de Energía, 2007). De ahí que los estudios de alternativas deban basarse en evaluaciones estratégicas previas que integren coordinadamente estudios de aptitud eólica, riesgos técnicos, medioambientales, administrativos y financieros, en la medida que suponen ahorros económicos y de tiempo muy significativos, a la vez que incrementan la seguridad de la inversión (Fernández Latorre, F., 1997). No hay que olvidar que los proyectos de parques eólicos tienen un periodo de 
madurez muy elevado, de 3 a 7 años desde que se detecta la posibilidad de negocio hasta que se inicia la explotación (Endesa-Escuela de Energía, 2007). El potencial eólico y solar del Sur del Mediterráneo puede convertir la región en un gran centro exportador de "negavatios" hacia Europa, evitando la consiguiente emisión de gases de efecto invernadero, y asentar un clúster industrial en el campo de las energías renovables. El proceso de transición hacia un modelo energético más sostenible está dando sus primeros pasos, como lo demuestran distintas iniciativas de gobiernos y agentes privados del espacio mediterráneo. Sobresalen, por su magnitud y repercusión, dos iniciativas regionales: el Proyecto Transgreen de interconexión de redes, y el Plan Desertec (Expansión, 2010). En ambas iniciativas participan empresas españolas, en concreto, Abengoa y Red Eléctrica de España (Medlognews, 2011a y 2010f). El Proyecto Transgreen, presentado en 2010, pretende reunir a las compañías eléctricas, operadores de redes y fabricantes de equipos de alta tensión bajo la dirección de la empresa francesa energética EDF, y realizar el plan de interconexión de redes entre las dos orillas del Mediterráneo. Turquía, de hecho, ha iniciado en 2010 la conexión al sistema de suministro eléctrico europeo (Medlognews, 2010d). Complementariamente, Desertec plantea una red de centrales solares fotovoltaicas y de concentración en el Norte de África para aprovechar el potencial de los desiertos. La red podría abastecer hasta un $15 \%$ de la energía requerida por Europa, así como el $65 \%$ de la necesaria para el Norte de África y Oriente Medio. Desertec no excluye la energía eólica aunque se centra fundamentalmente en la energía solar.

Figura 6. Esquema de anillo mediterráneo de la iniciativa Desertec

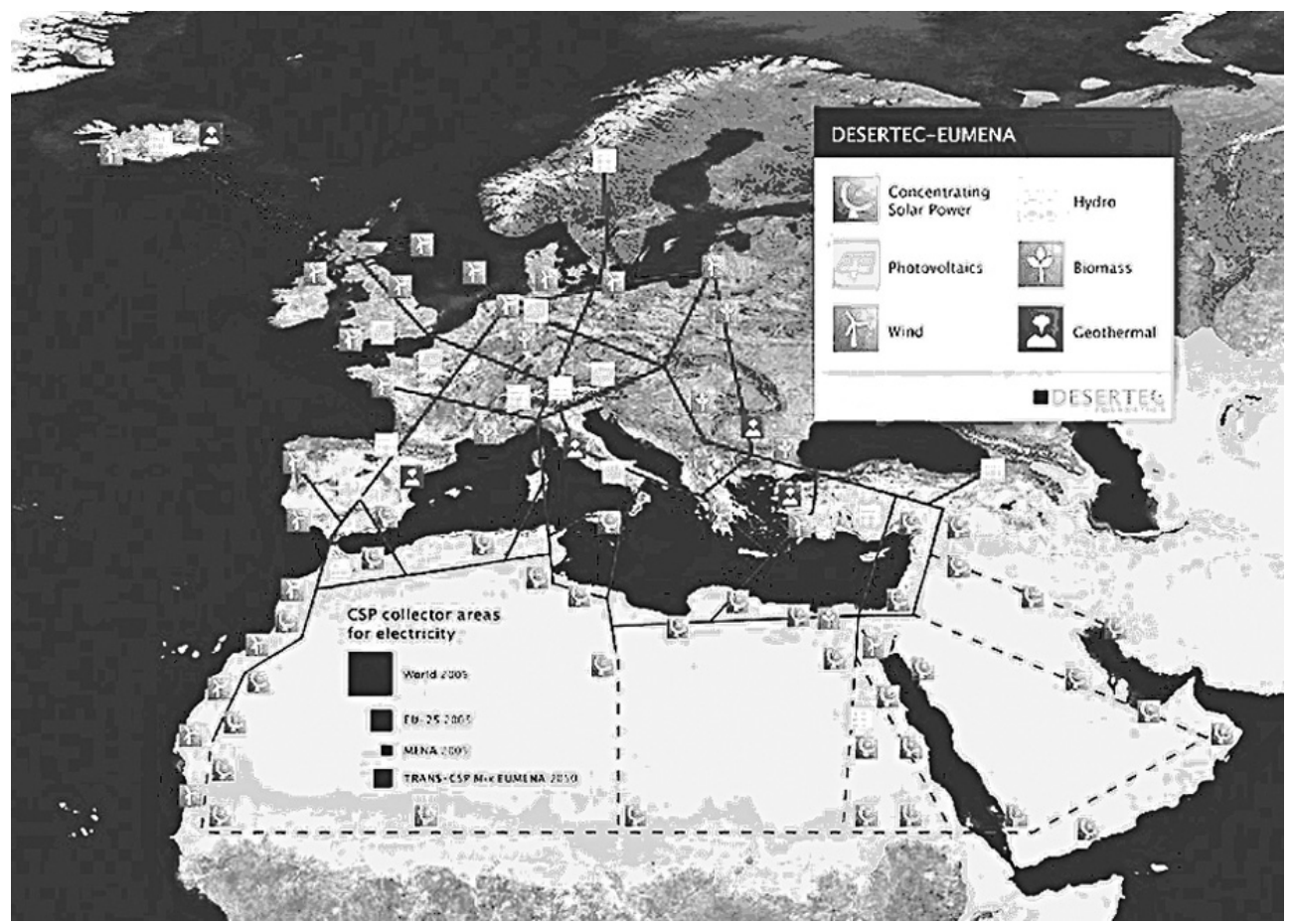

Fuente: Desertec Foundation (2011) 


\section{CONCLUSIONES}

Existe una clara disimetría entre recursos eólicos y el desarrollo de esta energía renovable en el entorno del Mediterráneo. El ranking del indicador Intensidad de Aprovechamiento Eólico está liderado por el mediterráneo occidental: España, Portugal e Italia; y por Turquía, seguido de Marruecos y Egipto, en el bloque mediterráneo árabe. España encabeza la potencia instalada, seguida de Italia, Francia y Portugal. Las potencias eólicas establecidas en comunidades autónomas españolas como Castilla-León son del orden de las Italia y Francia, la de la provincia de Cádiz supera a la de un país entero como Grecia, y Marruecos no llega ni siquiera al 10\% de la potencia eólica instalada en Andalucía. Los resultados obtenidos en países donde concurren abundantes recursos energéticos fósiles, como Libia y Argelia, o la prevalencia de la producción eléctrica nuclear, caso de Francia, sugieren el posible condicionamiento del desarrollo de energías renovables como la eólica, a causa de sus precios menores.

España, Marruecos, Egipto y Turquía se configuran como estados clave en el desarrollo eólico euromediterráneo por su situación geoestratégica, contar con un desarrollo eólico notorio (liderado por España), y políticas de promoción eólica. Marruecos, Egipto y Turquía muestran un alto potencial eólico no valorizado en comparación con la media de los países europeos mediterráneos. El potencial eólico del Sur del Mediterráneo puede convertir a la región en un gran centro exportador de "negavatios" hacia Europa, y asentar un cluster industrial eólico. Destacan dos grandes iniciativas privadas regionales: el Proyecto Transgreen de interconexión de redes, y el Plan Desertec. La Directiva 2009/28/CE, de 23 de abril, sobre fomento de las energías renovables, establece, para el año 2020, una cuota global para la Unión Europea del $20 \%$ de estas energías, y condiciona la electricidad producida a partir de fuentes de energía renovables en terceros países a la adecuada capacidad de evacuación de la red eléctrica internacional en la cuenca mediterránea. La aplicación de Mecanismos de Desarrollo Limpio en el espacio mediterráneo refuerza la Política Europea de Vecindad y posibilita la conexión del sistema energético europeo con el de los países extracomunitarios, en conjunción con la implementación efectiva del anillo eléctrico mediterráneo y el desarrollo de otras energías renovables como la solar, de elevado potencial en la región.

\section{BIBLIOGRAFÍA}

APREAN (2011): Observatorio Andaluz de Energías Renovables. Informe 2011.www.aprean.com/docs/observatorio/observatorio-andaluz-febrero2011.pdf BOUDGHENE STAMBOULI, A. (2011): Promotion of renewable energies in Algeria: Strategies and perspectives. Renewable and Sustainable Energy Reviews 15, pp. 1169-1181.

CANO GARCÍA, G. (2002): "Una propuesta de comarcalización para Andalucía", en Conocer Andalucía, Gran Enciclopedia Andaluza del Siglo XXI, volumen 10, Pueblos, Ciudades y Comarcas Andaluzas. Sevilla, Ed. Tartessos, pp. 11-85. 
CONSEJERÍA DE INNOVACIÓN, CIENCIA Y EMPRESA (2007): Plan Andaluz de Sostenibilidad Energética 2007-2013 (PASENER). Hacia un nuevo modelo energético. Consejería de Innovación, Ciencia y Empresa-Agencia Andaluza de la Energía.

CONSEJERÍA DE OBRAS PÚBLICAS Y VIVIENDA (2011): El Plan de Ordenación del Territorio de la aglomeración urbana de la Comarca del Campo de Gibraltar (en tramitación). http://www.juntadeandalucia.es/obraspublicasyvivienda/portal-web/web/areas/ordenacion Acceso: 22/05/2011

CDER (2007): Les ressources e'oliennes du Maroc.

DESERTEC FOUNDATION (2011): http://www.desertec . Acceso 21/08/2011.

DIPUTACIÓN DE CÁDIZ (2003): Plan Especial supramunicipal de ordenación de infraestructuras de los recursos eólicos en la comarca de La Janda (Cádiz). Diputación de Cádiz.

ENDESA-ESCUELA DE ENERGÍA (2007): Estudio de viabilidad técnico-económico de parques eólicos. http://www.escuelaendesa.com/pdf/9_estudio_viabilidad tecnico economico.pdf

ESPEJŌ MARĪN, C. (2004a): La energía eólica en España. Investigaciones Geográficas, no 35 , pp. 45-65.

ESPEJO MARÍN, C. (2004b): La electricidad en las relaciones España-Portugal. Finisterra, XXXIX, 78, pp.63-79.

EUROPEAN PARLIAMENT (2011). EU Energy Strategy in the South Mediterranean. ITRE. European Parliament.

EXPANSIÓN (2010): III Encuentro internacional Energías Renovables en Europa y Norte de África. Madrid, 25 y 26 de octubre de 2010.

FERNÁNDEZ LATORRE, F. (1997): Análisis metodológicos y cuantitativos para determinar la viabilidad técnico-ambiental de proyectos eólicos. Tecno ambiente, $\mathrm{n}^{\circ} 71$, pp. $30-31$

GALDÓS URRUTIA, R. y MADRID RUIZ, F.J. (2009): La energía eólica en España y su contribución al desarrollo rural. Investigaciones geográficas, $\mathrm{n}^{\mathrm{o}} 50$, pp. 93-108.

FAO (2011): http://faostat.fao.org

FONCUBIERTA RODRÍGUEZ, M.J. (2010): Origen de la gran industria en la comarca del Campo de Gibraltar. Historia Actual Online. No. 22, pp. 45-56.

FLUXÁ CEVA, J.M. y GÓMEZ LANDESA, E. (1995): La energía eólica en España. Revista de Obras Públicas. No. 3349 pp. 15-22.

FRITZSCHE, K., ET AL. (2011): The relevance of global energy governance for Arab countries: The case of Morocco. Energy Policy. Article in Press, pp. 1-10

GASTÓN M., PASCAL E. ET AL. (2008): Wind resources map of Spain at mesoscale. Methodology and validation. Proceedings of European Wind Energy Conference 2008, Brussels.

GLOBAL WIND ENERGY COUNCIL (2010): Global Wind Report. Annual market update 2010. Global Wind Energy Council.

GONZALO ESCRIBANO (2010): Vectores y sectores para la integración euromediterránea. Med.2010. 
HANELT, Christian-Peter (2010): Los vecinos de Europa en el Sur-Oriente Próximo como región de oportunidades. Spotlight europe 2010/10.

ICEX (2011): El sector de la energía eólica en Marruecos. Informes sectoriales. Oportunidades de inversión y cooperación empresarial.

MARKTANNER, M. y SALMAN, L. (2011): Economic and geopolitical dimensions of renewable vs. nuclear energy in North Africa. Energy Policy, doi:10.1016/j.enpol.2010.12.047.

MEDLOGNEWS (2010a): Egipto anuncia la construcción de una central nuclear de 900 MW junto al Mediterráneo.28-08-2010. http://www.medlognews.com

MEDLOGNEWS (2010b): Turquía ofrecerá 16.000 millones de euros en licencias para impulsar las energías renovables. 09-09-2010. http://www.medlognews.com

MEDLOGNEWS (2010c): Gestamp construirá torres eólicas en Turquía. 09-092010. http://www.medlognews.com

MEDLOGNEWS (2010d): Turquía conecta su red eléctrica a Europa. 22-09-2010. http://www.medlognews.com

MEDLOGNEWS (2010f): Marruecos se suma al proyecto para crear una red eléctrica transmediterránea.01-10-2010. http://www.medlognews.com

MEDLOGNEWS (2011a): Los bancos italianos Unicredit e Intesa Sanpaolo se suman al p Proyecto Desertec. 22-02-2011. http://www.medlognews.com

MEDLOGNEWS (2011b): La consultora AF Mercados EMI asesorará a Marruecos, Túnez y Argelia en las energías renovables.12-04-2011. http://www.medlognews.com

MEDLOGNEWS (2011c): Seis entidades europeas estudian la creación de un fondo para promover proyectos 'verdes' en el Mediterráneo. 2010-06-21. http://www.medlognews.com

MINISTERIO DE INDUSTRIA, TURISMO Y COMERCIO-IDAE (2010): Plan de Acción Nacional de Energías Renovables de España (PANER) 2011-2020. Ministerio de Industria, Turismo y Comercio-IDEA.

MINISTERIO DE INDUSTRIA, TURISMO Y COMERCIO y MINISTERIO DE MEDIO AMBIENTE Y MEDIO RURAL Y MARINO (2009): Estudio estratégico ambiental del litoral español para la instalación de parques eólicos marinos. Ministerio de Industria, Turismo y Comercio y Ministerio de Medio Ambiente y Medio Rural y Marino

OFFICE NATIONAL DE L'ELECTRICITÉ (2010): Project marocaine de l'énergie eolienne. Www.one.org.ma.

PWC-PRICEWATERHOUSE COOPERS (2010): 100\% renewable electricity. A roadmap to 2050 for Europe and North Africa, PWC, Londres.

REACCESS-UNED (2009): The Europeanization of MS'Energy Security Policies, REACCESS Project.

RED ELÉCTRICA DE ESPAÑA (2010): El sistema eléctrico español. Avance del informe 2010. Red Eléctrica De España.

REGATO, P. (2008): Adaptación al cambio global. Los bosques mediterráneos. IUCN STRONG, Maurice (1992): Energy, Environment and Development. Energy Policy, vol. $20, n^{\circ} .6$. 
TOSCANO BENAVIDES, L. (2000): Planificación territorial y desarrollo eólico. Andalucía Ecológica, abril-2000.

UNEP (2010): Global Trends in Sustainable Energy Investment 2010. Analysis of Trends and Issues in the Financing of Renewable Energy and Energy Efficiency. UNEP.

VENTURA FERNÁNDEZ, J. y MORENO NAVARRO, J.G. (2004): Entorno regional e inserción territorial del nuevo puerto Tánger-Mediterráneo: elementos para su competitividad, para el Schema Directeur d'aménegement Urbain du Detroit (SDAUD), dirigido por Fathallah Debbi y Najib Mekouar.

YÜKSEL, I. (2008): Global warming and renewable energy sources for sustainable development in Turkey. Renewable Energy 33, Technical Note. pp. 802-812.

WORLD WIND ENERGY ASSOCIATION (2011): World Wind Energy Report 2010. World Wind Energy Association. 